\title{
Trapezius muscle rest time during standardised computer work - A comparison of female computer users with and without self-reported neck/shoulder complaints
}

\author{
S. Thorn ${ }^{a, b, *}$, K. Søgaard ${ }^{c}$, L.A.C. Kallenberg ${ }^{\text {d }}$, L. Sandsjö ${ }^{a, b}$, \\ G. Sjøgaard ${ }^{\mathrm{c}}$, H.J. Hermens ${ }^{\mathrm{d}}$, R. Kadefors ${ }^{\mathrm{a}, \mathrm{b}}$, M. Forsman ${ }^{\mathrm{a}, \mathrm{b}}$ \\ ${ }^{a}$ National Institute for Working Life, Box 8850, SE 40272 Göteborg, Sweden \\ ${ }^{\mathrm{b}}$ Department of Product and Production Development, Chalmers University of Technology, Göteborg, Sweden \\ ${ }^{\mathrm{c}}$ National Institute of Occupational Health, Copenhagen, Denmark \\ ${ }^{\mathrm{d}}$ Roessingh Research and Development, Enschede, The Netherlands
}

Received 8 September 2005; received in revised form 5 April 2006; accepted 18 April 2006

\begin{abstract}
Work related musculoskeletal disorders (WMSDs) in the shoulder/neck area are a common and increasing problem among European computer workers, especially women. Long-term low-level workloads with low degree of muscle rest are a potential risk factor for developing WMSDs. The purpose of the present study of female computer users (age 45-65 years) in Denmark and Sweden was to investigate if subjects with self-reported neck/shoulder complaints (cases, $N=35$ ) show less trapezius muscle relative rest time (RRT) than controls $(N=44)$ when performing standardised short-term computer work tasks in controlled laboratory conditions. Surface electromyography (EMG) signals were recorded bilaterally from the upper trapezius muscles during a type, edit, precision and colour word stress task. Besides RRT, 10th percentile RMS values were calculated. On the average, 15 of the cases and 18 of the controls showed analysable EMG files per task. For the colour word stress task, the results showed lower RRT values and higher 10th percentile RMS amplitude levels among cases compared to controls. No such signs could be found for the other tasks performed. The present results indicate an increased motor response to a psychological stressor among subjects with self-reported neck/shoulder complaints.
\end{abstract}

(C) 2006 Elsevier Ltd. All rights reserved.

Keywords: Muscle rest; EMG; Computer work; Musculoskeletal disorders

\section{Introduction}

Work related musculoskeletal disorders (WMSDs) in the shoulder/neck area are a common problem among European computer workers, especially women (e.g., Jensen et al., 2002; Wigaeus Tornqvist et al., 2001), in spite of the relatively low muscle activation levels required. The use of computers at work has increased substantially during the last decade, and several studies report aug-

\footnotetext{
${ }^{*}$ Corresponding author. Present address: National Institute for Working Life, Box 8850, SE 40272 Göteborg, Sweden. Tel.: +46 315016 48; fax.: +46 31501610 .

E-mail address: stefan.thorn@arbetslivsinstitutet.se (S. Thorn).
}

mented problems with increased computer usage (Blatter and Bongers, 2002; Fogleman and Lewis, 2002; Jensen, 2003; Wigaeus Tornqvist et al., 2001).

The Cinderella hypothesis postulates that long-term low-level workloads with low degree of muscle rest can cause selective over-usage of low-threshold muscle fibres, leading to WMSDs (Hägg, 1991). Based on this theory, it has been hypothesised that a low degree of muscle rest is a risk factor for development of WMSDs. This hypothesis is supported by a one-year prospective study of light manual work (Veiersted et al., 1993), where surface electromyography (EMG) was recorded and a regression analysis showed that a low amount of short muscle rest periods (gaps) predicted future development of WMSDs. More- 
over, an extensive prospective study of computer users showed a significant association between perceived muscular tension and an increased risk for developing neck pain (Wahlström et al., 2004). A low degree of muscle rest may persist also after the development of disorders or complaints. Significantly higher median trapezius EMG activity and a tendency towards lower degree of muscle rest has been reported from computer users who perceived muscular tension at least a few times per week during the past month (Wahlström et al., 2003). In cross-sectional field studies of medical secretaries (Hägg and Åström, 1997) and cashier workers (Sandsjö et al., 2000) performing ordinary work activities, significantly lower muscle rest was demonstrated among workers with self-reported shoulder/neck complaints compared to those without. Two similar studies of office workers (Nordander et al., 2000; Vasseljen and Westgaard, 1995), however, did not support these results. Since these studies mainly were performed in daily life situations, this inconsistency might be related to inter-individual differences that are hard to control, e.g., work tasks, ergonomic environment, etc. Comparative studies of muscle rest during standardised computer work tasks in controlled environment are therefore of high interest since they can show which physical and mental demands may trigger different muscular behaviour among workers with self-reported shoulder/neck complaints compared to those without. Currently, such studies are lacking. In the EU funded project 'Neuromuscular Assessment of the Elderly Worker (NEW)' (Merletti et al., 2004), EMG data have been assessed from female computer workers during standardised computer work in laboratory setup. The project included cross-sectional data from women with self-reported neck/shoulder complaints (cases) and those without (controls). The objective of the present study was to utilise data collected in the NEW project to investigate if cases show less muscular relative rest time (RRT) than controls when performing standardised, short-term (2$5 \mathrm{~min}$ ) computer work tasks with various elements of physical and mental demands.

\section{Method}

Data from questionnaires and physical measurements from elderly female computer users (defined as age 45-65 years) in Denmark and Sweden were analysed. In Denmark, the participants were employees of an insurance company, a ministry department, or an administrative unit at a hospital. The participants in Sweden were employees of a regional branch of the Swedish National Labour Market Administration. To be included in the present study, the computer users were required to: (1) have worked at least 5 years with computer job tasks, (2) work at least $20 \mathrm{~h}$ a week, and (3) have less than 3 months out of work, except for vacation, during the last 5 years. A division into neck/shoulder cases and controls was made using selfreported data from the standardised nordic musculoskeletal questionnaire (NMQ) (Kourinka et al., 1987). The inclusion criteria for cases were: (1) neck/shoulder complaints for more than 30 days during the past year, and (2) less than three additional body regions with complaints $>30$ days. The inclusion criteria for controls were: (1) less than 8 days of complaints in the neck/shoulder area during the past year, and (2) less than three additional body regions with complaints $>30$ days. The controls may be regarded rather as non-cases, since they are not general population controls. For simplicity in terminology we will, however, retain the term controls.

In total, 79 subjects ( 35 cases, 44 controls) were studied. Mean age was 53.3 (SD: 5.0) years for cases and 55.6 (4.9) years for controls. The average body mass index (BMI) was $25.7(3.9)$ and $24.6(3.1) \mathrm{kg} / \mathrm{m}^{2}$ for cases and controls, respectively. For each work task, on the average 15 (range: 14-16) of the cases and 18 (12-21) of the controls showed analysable EMG files (Table 1). The typing and editing tasks rendered the fewest number of analysable files. Most common reasons for disregarding the files were too low signal-to-noise ratio and/or $50 \mathrm{~Hz}$ disturbance problems (maximum signal amplitude less than 3 times the disturbance amplitude with the muscle at rest). For the group

Table 1

Median and P10 RMS activity levels and RRT results for cases vs. controls on mouse and non-mouse side of the trapezius muscle

\begin{tabular}{|c|c|c|c|c|c|c|c|c|}
\hline \multirow{2}{*}{$\begin{array}{l}\text { Variable } \\
\text { Task }\end{array}$} & \multicolumn{2}{|c|}{$\begin{array}{l}\text { Number of } \\
\text { subjects }\end{array}$} & \multicolumn{2}{|c|}{$\begin{array}{l}\text { Median RMS activity level } \\
(\% \text { MVE) }\end{array}$} & \multicolumn{2}{|c|}{ P10 RMS activity level (\%MVE) } & \multicolumn{2}{|c|}{ RRT result (\% time) } \\
\hline & Case & Control & Case & Control & Case & Control & Case & Control \\
\hline \multicolumn{9}{|c|}{ Trapezius mouse side } \\
\hline Typing & 14 & 19 & $9.9(5.4-28.2)$ & $8.7(3.0-16.0)$ & $5.7(1.3-19.8)$ & $5.7(0.9-8.9)$ & $0.1(0-6.7)$ & $0.1(0-12.3)$ \\
\hline Editing & 14 & 12 & $8.5(1.9-30.8)$ & $8.0(4.7-15.4)$ & $4.3(1.0-17.9)$ & $4.3(1.1-8.1)$ & $0.3(0-9.5)$ & $0.2(0-9.4)$ \\
\hline Precision & 15 & 21 & $3.5(1.0-6.4)$ & $2.0(0.7-5.4)$ & $1.6(0.6-4.0)$ & $1.0(0.3-3.7)$ & $3.5(0-53.8)$ & $12.1(0-70.1)$ \\
\hline Stress & 15 & 21 & $3.1(0.8-12.3)$ & $1.4(0.6-7.9)^{\#}$ & $1.2(0.4-6.3)$ & $0.6(0.2-4.1)$ & $4.5(0-68.8)$ & $33.7(0.5-84.1)^{*}$ \\
\hline \multicolumn{9}{|c|}{ Trapezius non-mouse side } \\
\hline Typing & 14 & 18 & $8.6(5.4-9.9)$ & $7.5(4.5-14.7)$ & $4.9(2.5-7.0)$ & $4.3(1.5-6.8)$ & $0(0-1.0)$ & $0.3(0.1-6.2)$ \\
\hline Editing & 14 & 12 & $6.6(2.2-8.5)$ & $7.0(3.5-11.4)$ & $2.5(0.7-4.8)$ & $2.9(1.7-6.1)$ & $2.8(0-15.9)$ & $1.0(0-5.0)$ \\
\hline Precision & 15 & 20 & $1.0(0.6-2.9)$ & $1.4(0.7-4.5)$ & $0.5(0.3-2.1)$ & $0.5(0.2-1.7)$ & $55.6(0.7-76.3)$ & $39.9(1.3-75.5)$ \\
\hline Stress & 16 & 21 & $2.1(1.1-4.9)$ & $1.8(0.6-2.4)$ & $1.1(0.4-1.8)$ & $0.6(0.3-1.0)^{\#}$ & $8.1(3.0-42.9)$ & $26.8(10.9-82.2)^{\ddagger}$ \\
\hline
\end{tabular}

Group median values (lower-upper quartiles) are shown. ${ }^{*}$ Indicates cases significantly different from controls, ${ }^{*}$ indicates a tendency of a corresponding difference $(p<0.1)$. 
of subjects with analysable files, the average age was 52.7 years for cases and 54.2 years for controls. The corresponding BMI values were on the average 25.0 and $24.0 \mathrm{~kg} / \mathrm{m}^{2}$, respectively. None of these values differed significantly to those representing all 79 subjects. No differences in age or BMI between cases and controls were found for any of the work tasks analysed. The large amount of unusable EMG data are further addressed in Section 4.

The local research ethics committees approved this study. All subjects were fully informed about the experimental procedures before giving their consent, and were fully allowed to interrupt or leave the study whenever they wanted to. These subjects constitute a sub-sample of the subjects with general EMG results previously reported by Sjøgaard et al. (2006).

\subsection{Electromyography}

Two adhesive linear arrays (ELSCH008, LISiN-SPES Medica, Italy) (Pozzo et al., 2004) consisting of eight $2.5 \times 1 \mathrm{~mm}$ rectangular surface $\mathrm{Ag} / \mathrm{AgCl}$ EMG electrodes with $5-\mathrm{mm}$ inter-electrode distance (IED) were placed over the upper trapezius muscle on the side operating the computer mouse (mouse side) and on the side not operating the mouse (non-mouse side). The arrays were aligned on the line from the dorsal processus of the seventh cervical vertebra (C7) towards the acromion, with the most medial electrode approximately $5 \mathrm{~mm}$ lateral to the midpoint between C7 and acromion. Conductive gel was injected into each electrode cavity by means of a gel dispenser. A reference electrode was placed at the wrist. Before array placement, the skin was slightly abraded with abrasive paste (Meditec-Every, Parma, Italy). Seven-channel bipolar single-differential EMG was sampled from each muscle with a frequency of $2048 \mathrm{~Hz}$ and was 16-bit A/D converted on a prototype portable acquisition system (EMGlogger, LISiN - Sirio Automazione, Torino, Italy) (Pozzo et al., 2004). The amplifier had a gain of $1000,<1 \mu \mathrm{V}_{\mathrm{RMS}}$ noise in the frequency band studied, common mode rejection ratio (CMRR) of $90 \mathrm{~dB}$ at $50 \mathrm{~Hz}$, and an input impedance of $10 \mathrm{G} \Omega / / 4 \mathrm{pF}(>100 \mathrm{M} \Omega$ at $500 \mathrm{~Hz})$.

\subsection{Protocol}

The protocol started with an EMG measurement during a rest period of $20 \mathrm{~s}$. This was used in the determination of noise level. After that, EMG was measured during four different computer work tasks, (1a, 1b, 2 and 3), where the order of tasks $1-3$ was randomised:

1. Text typing (1a) of a standard text, followed by editing (1b) of the previously typed text according to a standard procedure (Juul-Kristensen et al., 2004). Each tasks lasted until completion or $5 \mathrm{~min}$.

2. A precision task, where the subjects were asked to connect points according to a template by clicking on the points in the right order with the computer mouse (Birch et al., 2000). New points and a new template appeared on the computer screen after each figure was finished correctly. The subjects were asked to finish as many figures as possible. The task lasted for $2 \mathrm{~min}$.

3. A Stroop colour word stress task (Laursen et al., 2002; Stroop, 1935), where the name of a colour appeared approximately once a second at a random place on the computer screen. By clicking on the correct of four icon alternatives with the computer mouse, the subjects were asked to respond in which colour the word was written. An audio alarm sounded when the response was erroneous or when the time limit to answer was exceeded. The task lasted for $5 \mathrm{~min}$.

For EMG normalisation purposes, the subjects were then asked to perform three maximum voluntary contractions (MVCs). If the third MVC recording was more than 5\% higher than the previous two recordings, a fourth test was performed; a maximum of 5 tests were performed. For further details, see Sjøgaard et al. (2006). The maximum voluntary electrical (MVE) activity was computed according to recommendations by Mathiassen et al. (1995).

The typing task consisted of keyboard work, while the editing task was a mixture of keyboard and mouse work. The precision and stress tasks were entirely mouse work. The subjects were free to choose work posture, as well as hand operating the computer mouse. In between the tasks, subjects were allowed to rest for approximately $2 \mathrm{~min}$.

\subsection{Signal processing}

Prior to further analysis, the signals were visually inspected in order to determine whether to remove short artefact periods or if any of the 5-mm IED signals needed to be disregarded due to e.g., poor signal-to-noise ratio and/or $50-\mathrm{Hz}$ powerline disturbances. Due to low- and high frequency disturbances (at $16 \mathrm{~Hz}$ and $320 \mathrm{~Hz}$, respectively), originating from EMG hardware, a 6th order Butterworth $20-300 \mathrm{~Hz}$ band pass filter was applied to the signals. Additionally, an adaptive $50 \mathrm{~Hz}$ rejection filter (Mortara, 1977) was used for removal of powerline interferences.

By praxis, an IED of $20 \mathrm{~mm}$ is recommended for extracting parameters from bipolar surface EMG on the upper trapezius muscle (e.g., Freriks et al., 1999). For each electrode array, the 5-mm IED bipolar signals were therefore converted to four different 20-mm IED bipolar signals as:

$s 20_{i}=\sum_{k=0}^{3} s 5_{i+k} \quad i=1,2,3,4$

with $s 20_{i}$ being the $i$ th 20 -mm IED signal and $s 5_{i+k}$ the $(i+k)$ th 5 -mm IED signal. From visual inspection, the signal of best quality of these four was chosen. The complete file was disregarded in case of no usable combinations of four consecutive 5-mm IED signals. Root mean square (RMS) values from 100-ms non-overlapping windows were 
calculated for the chosen $s 20$ signal. The RMS values were, in a power sense, subtracted by the recorded noise level as:

$\operatorname{RMS}(j)=\sqrt{\operatorname{RMS}(j)^{2}-\text { noise }^{2}}$

where $j$ is the $100-\mathrm{ms}$ window number. For each subject, the noise level used for all trials was defined as the minimum 500-ms RMS value across all trials.

RRT was defined as the relative cumulative time with RMS amplitudes below $1 \%$ MVE for periods of $\geqslant 100 \mathrm{~ms}$. The $1 \%$ MVE threshold level has previously been found to be sensitive to individual differences in terms of gap frequency analysis (Hansson et al., 2000). The 10th percentile (P10) RMS levels were calculated as an indicator of static activity according to Jonsson (1982). All signal processing was performed in MATLAB (MathWorks Inc., USA).

\subsection{Statistics}

Statistical analysis was performed in SPSS (SPSS Inc., USA) and MATLAB. For normally distributed data, descriptive statistics were given by mean and standard deviation (SD), and possible differences between groups were tested by paired and non-paired $t$-tests. For non-normally distributed data, non-parametric statistics (Wilcoxon and Mann-Whitney tests) were applied. Correlation between P10 RMS levels and RRT values was assessed to investigate the P10 relatedness to muscle rest. The chosen level of significance was $p<0.05$. Additionally, $p<0.1$ was chosen as the limit to indicate tendency of differences. In cases of multiple comparisons, Bonferroni corrections of the $P$ levels were applied.

\section{Results}

For cases and controls together, the absolute MVE RMS levels on the s20-signals were on the average

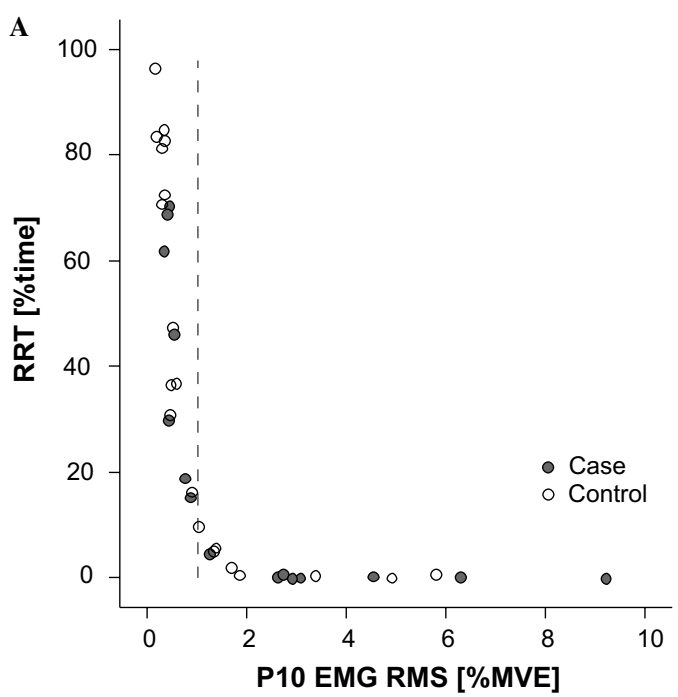

$400 \mu \mathrm{V}$ and $360 \mu \mathrm{V}$ on mouse and non-mouse side, respectively. The recorded s20 noise RMS levels were on average $5.4 \mu \mathrm{V}$ on mouse side and $5.8 \mu \mathrm{V}$ on non-mouse side, corresponding approximately to 1.4 and $1.6 \% \mathrm{MVE}$, respectively. Neither MVE nor noise RMS levels differed significantly between cases and controls.

The median and P10 RMS activity levels and RRT results during the typing, editing, precision and stress tasks, separated for cases vs. controls, are shown in Table 1.

As shown by the large range between the lower and upper quartiles in Table 1, large individual differences in median RMS, P10 RMS and RRT results were found for both cases and controls. The median and P10 RMS levels were significantly higher during the typing and editing tasks compared to precision and stress tasks on both sides of the trapezius and for both cases and controls. The group median RRT results were much lower for the typing and editing tasks compared to precision and stress tasks. These differences were statistically significant, except for controls on non-mouse side comparing editing vs. precision and for cases on mouse side comparing typing vs. precision. For cases, both median and P10 RMS levels were significantly higher on mouse side compared to non-mouse side during all four tasks. For both cases and controls, the RRT results tended $(p<0.1)$ to be lower on mouse side compared to non-mouse side during the precision task, while no tendencies were found for the other tasks.

For the stress task on mouse side, significantly lower RRTs were found for cases. Here, there was also a tendency for higher median RMS levels for cases than for controls $(p<0.1)$, and P10 RMS levels were on the average higher for cases with a relatively low $p$-value $(p<0.13)$. On non-mouse side, there was a tendency for higher P10 RMS levels and lower RRT results for cases compared to controls $(p<0.1)$. During the typing, editing and precision tasks, no differences between cases and controls were found.

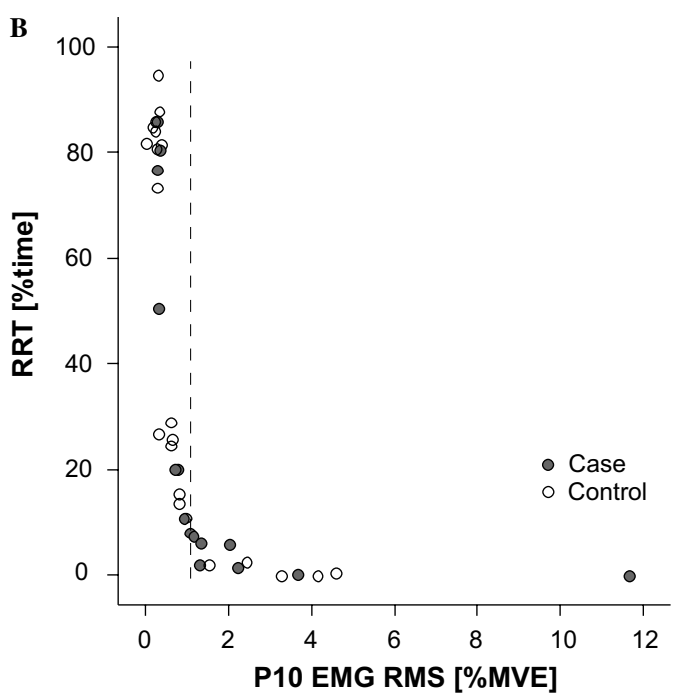

Fig. 1. Scatter plots of the individual P10 RMS levels and RRT values on mouse side (A) and non-mouse side (B) for the stress task. The dashed vertical lines mark RRT threshold level ( $1 \% \mathrm{MVE})$. 
The P10 RMS levels correlated significantly with the RRT values on both non-mouse and mouse side for all tasks (Spearman test; $p<0.001, \rho_{\mathrm{s}}$ ranging between -0.81 and -0.95 ) with an inverse relationship, see example in Fig. 1.

\section{Discussion}

In this experimental study with standardised, short-term work tasks, the main finding was that elderly female computer users with self-reported neck/shoulder complaints showed several electromyographic signs for less trapezius muscle rest compared to those without complaints, when performing a short-term colour word stress task, but not during the more physical tasks.

\subsection{Overall muscle activity}

As presented above, the median muscle activity was slightly below $10 \%$ MVE during the typing and editing tasks, and around $2 \% \mathrm{MVE}$ during the precision and stress tasks on both the mouse and the non-mouse side. The subjects in the present study constitute a sub-sample of a larger study of 252 elderly computer users from Denmark, the Netherlands, Sweden and Switzerland (Sjøgaard et al., 2006). In that study, no significant differences between cases and controls were found in absolute values of mean EMG RMS levels during the computer tasks. When normalizing the RMS data from the computer tasks with the values attained during a $30 \% \mathrm{MVC}$ and assuming linearity between RMS levels and force development, it was further estimated that the average relative muscle activation was $10-11 \% \mathrm{MVE}$ in the trapezius muscle during typing, 7$8 \% \mathrm{MVE}$ during editing, and 3-4\%MVE during the precision and stress tasks. No differences were found between cases and controls (Sjøgaard et al., 2006).

The present P10 levels were approximately half of the corresponding median levels, which indicate a high degree of static activity (Jonsson, 1982) during the tasks. Previous studies of muscular activity among computer workers performing regular work at their workplace have reported median activities of approximately 4 and $2 \% \mathrm{MVE}$ on the mouse and the non-mouse side, respectively, among computer-aided design (CAD) operators (Jensen et al., 1998), and of 3.6 and $3.3 \% \mathrm{MVE}$, respectively, among female office assistants (Blangsted et al., 2003). Corresponding P10 levels were 1 and $0.3 \% \mathrm{MVE}$, respectively, for the CAD operators, and 1.1 and $1.0 \% \mathrm{MVE}$, respectively, for the female office assistants. Thus, especially the typing and editing work tasks chosen in the present study may represent rather physically intensive and static computer tasks.

\subsection{Muscle rest}

A high degree of static activity during the performed tasks, as indicted above, would explain the general result of lower median RRTs during the typing and editing tasks compared to the precision and stress tasks.

In contrast to the typing and editing tasks, the precision and stress task consist entirely of mouse work with no taskrelated activity required on the non-mouse side of trapezius. Therefore, the findings of higher RRT on non-mouse side compared to mouse side during the precision task, but not during the stress task, indicate that mental stress induces more bilateral constant activity compared to a precision mouse task. The lower RRT values and higher P10 RMS levels among cases compared to controls during the stress task further suggest that the stress induced constant activity is higher for cases than for controls, both on the contra-lateral and the primary side of the trapezius. The strong negative correlations between P10 RMS levels and RRT values for all tasks and on both sides of trapezius substantiate the P10 RMS relatedness to muscle rest.

Previous cross-sectional field studies of medical secretaries (Hägg and Åström, 1997) and cashier workers (Sandsjö et al., 2000), who were performing ordinary work activities at their workplace, have reported significantly lower RRT among workers with self-reported shoulder/neck complaints compared to those without. In the present results, different RRT and RMS levels between cases and controls were indicated for the stress task, but not for the typing, editing or precision tasks. The relatively intensive and static physical demands during the typing and editing tasks, and the shorter recording time during the precision task, may have masked eventual differences in muscle activities between cases and controls. Due to the short-cycled and highly repetitive design of the precision task, the latter is however less probable. An alternative explanation is that subjects with self-reported neck/shoulder complaints are more prone to develop a stress-related trapezius muscle activity than healthy subjects, i.e., an increased motor response to psychological stress in tender muscles. In a study of 62 subjects with trapezius muscle myofascial trigger points, spontaneous needle EMG activity was reported from all trigger points but not from adjacent non-tender fibres of the same muscle in the same subject (Hubbard and Berkoff, 1993). It was postulated that the trigger point activity was generated from sympathetically stimulated muscle spindles, which is further supported by findings of increased trigger point activity during psychological stress while adjacent non-tender trapezius muscle fibres remained electrically silent (McNulty et al., 1994).

As previously presented by Veiersted et al. (1993), lack of muscle rest periods is a plausible risk factor for development of WMSDs. Due to the cross-sectional design of the present study, it cannot be stated whether the cases showed less muscle rest than controls also before the complaints developed. Veiersted et al. (1993) showed that the number of short muscle rest periods were significantly lower for the patients, also before patient status. Moreover, a prospective study of light manual workers in the poultry and fish industries showed higher mean shoulder muscle EMG activity both prior to and after the start of complaints 
among workers who later developed neck/shoulder complaints presented, compared with workers who stayed healthy (Madeleine et al., 2003). With support from these longitudinal findings, the present results indicate that stressful working conditions may exacerbate muscular overuse in people who already experience neck/shoulder complaints.

\subsection{EMG dropouts}

As presented in Methods, a large quantity of the EMG data could not be analysed, mainly due to poor signal-tonoise ratio and/or $50 \mathrm{~Hz}$ interference problems. One of the objectives with the NEW project, outside the scope of the present study, was to investigate non-invasive techniques to estimate muscle fibre conduction velocity $(\mathrm{CV})$ among elderly computer users. For this reason, a 7-channel bipolar linear array electrode with $5 \mathrm{~mm}$ IED was used. The electrode was at a prototype stage and not pre-gelled. The main reason for the EMG dropouts was most probably an increased risk for insufficient electrode-to-skin contact, due to too little amount of electrode gel applied, or shortcircuiting, due to too much electrode gel applied in the cavities of the array, as compared to pre-gelled electrodes at $20 \mathrm{~mm}$ IED for normal surface EMG use (Freriks et al., 1999). The 5-mm IED bipolar spatial filtering, and the conversion from s 5 to 20 signals further decrease the signal-tonoise ratio. The recorded noise level corresponded, on the average, to approximately $1.5 \% \mathrm{MVE}$ in the analysable data. Thus, a compensation of RMS levels to recorded noise was needed. Neither age nor BMI differed significantly for the group of subjects with analysable EMG data as compared to the group of all subjects. Moreover, the number of EMG dropouts was similar for cases as for controls. Due to the nature of the EMG dropouts as described above, the present results are judged to be representative for the whole group of investigated cases/controls.

\subsection{Self-reported complaints vs. muscular disorders}

Complaints in the neck/shoulder region, reported by use of the NMQ questionnaire, are not necessarily related to disorders localised to muscle tissue. However, a clinical investigation of the studied subject group reported that trapezius muscle pain (myalgia) and tension neck syndrome were the two most frequent clinical diagnoses among cases (Juul-Kristensen et al., 2006). In total, muscle disorders could be diagnosed for $60 \%$ of the cases and for only $7 \%$ of the controls. Thus, a relation between self-reported neck/shoulder complaints and muscular disorders is substantiated in the studied subject group.

\subsection{Protocol}

In the present study, the standardised computer work tasks were developed as tests similar to occupational tasks in computer worker's daily life. Previous comparative studies of muscle rest (e.g., Blangsted et al., 2003; Hägg and
Åström, 1997; Nordander et al., 2000; Sandsjö et al., 2000; Vasseljen and Westgaard, 1995) are mostly of longterm character and carried out at the subject's ordinary workplace during their regular work. Field studies like these facilitate estimation of the individual's actual workload during their working hours. However, a comparative analysis of workload between subject groups (e.g., cases vs. controls) is at risk to be hampered by factors difficult to control at the workplace. For example, work tasks, psychosocial factors, ergonomic environment, etc., can differ between individuals, subject groups, and days. A field study of employees in municipal administration has shown that differences in muscle rest predominantly were due to differences in job content, even though all performed computer work (Blangsted et al., 2003). Comparative studies in controlled laboratory environment and with standardised computer work tasks, as in the present study, are therefore of a high interest.

For practical reasons, the work tasks lasted for 2-5 min. Theoretically, a prolongation of the work tasks would gain precision of a group mean value. However, the present work tasks were highly standardised and of short cycles, which potentially reduced the significance of prolonging the work tasks. Results from 10 subjects performing a standardised computer work task showed that, taken a standard measurement time of $5 \mathrm{~min}$, the number of subjects is more effective to increase than the measurement time (Forsman et al., 2006).

\subsection{Signal processing}

As described in Method, there were disturbances at $16 \mathrm{~Hz}$ and at $320 \mathrm{~Hz}$ in the power spectrum, originating from the EMG hardware applied. The magnitudes of the disturbances varied with time and subject, and the most effective and robust technique found for reducing these disturbances was by applying a digital band pass filter at $20-300 \mathrm{~Hz}$. The reason for using the specific low- and high cut-off frequencies was the sensitivity of the RRT algorithm for noise. The effects of this slightly different filter settings - as compared to the Journal's normal standards - on the RMS values were considered low and consistent between the subjects, and would not hamper the comparison between the two groups of subjects, which was the objective of the study.

\section{Conclusion}

In conclusion, elderly female computer users with selfreported neck/shoulder complaints showed several electromyographic signs for less trapezius muscle rest compared to those without complaints, during performance of a short-term colour word stress task under controlled laboratory conditions. For the short-term typing, editing, and precision tasks, no such signs could be found. Lack of muscle rest periods has previously been reported as a plausible risk factor for the development of WMSDs. The present results indicate an increased motor response 
to a psychological stressor among subjects with selfreported neck/shoulder complaints.

\section{Acknowledgements}

The authors acknowledge Henrik Baare Olsen and Susan Utriainen for their support during the data collection and analysis. Contributions by colleagues at the Institute of $\mathrm{Hy}-$ giene and Applied Physiology at ETH in Zürich, the LISiN Laboratory of Engineering of Neuromuscular System and Motor Rehabilitation at Politecnico di Torino in Turin, and the Helmholtz Institute for Biomedical Engineering in Aachen, are gratefully acknowledged. This work was undertaken within the project 'Neuromuscular Assessment of the Elderly Worker (NEW)', with partial financial support from the EC within the RTD action QRLT 200000139.

\section{References}

Birch L, Juul-Kristensen B, Jensen C, Finsen L, Christensen H. Acute response to precision, time pressure and mental demand during simulated computer work. Scand J Work Environ Health 2000;26:299-305.

Blangsted AK, Hansen K, Jensen C. Muscle activity during computerbased office work in relation to self-reported job demands and gender. Eur J Appl Physiol 2003;89:352-8.

Blatter BM, Bongers PM. Duration of computer use and mouse use in relation to musculoskeletal disorders of neck or upper limb. Int J Ind Ergonom 2002;30:295-306.

Fogleman M, Lewis RJ. Factors associated with self-reported musculoskeletal discomfort in video display terminal (VDT) users. Int J Ind Ergonom 2002;29:311-8.

Forsman M, Anteborn G, Thorn S. Variability in electromyographic measurements within and between individuals performing a computer work task. Accepted for presentation at the 16th World Congress on Ergonomics. International Ergonomics Association (IEA), Maastricht, 2006.

Freriks B, Hermens H, Disselhorst-Klug C, Rau G. The recommendations for sensors and sensor placement procedures for surface electromyography. In: Hermens H, Freriks B, Merletti R, Stegeman D, Blok J, Rau G, Disselhorst-Klug C, Hägg G, editors. SENIAM Deliverable 8 - European Recommendations for Surface ElectroMyoGraphy. Enschede: Roessingh Research and Development; 1999. p $15-4$.

Hägg GM. Static work loads and occupational myalgia - a new explanation model. In: Anderson PA, Hobart DJ, Danoff JV, editors. Electromyogr kinesiol. Amsterdam: Elsevier Science; 1991. p. 141-3.

Hägg GM, Åström A. Load pattern and pressure pain threshold in the upper trapezius muscle and psychosocial factors in medical secretaries with and without shoulder/neck disorders. Int Arch Occup Environ Health 1997;69:423-32.

Hansson G- $\AA$, Nordander C, Asterland P, Ohlsson K, Strömberg U, Skerfving S, Rempel D. Sensitivity of trapezius electromyography to differences between work tasks - influence of gap definition and normalisation methods. J Electromyogr Kinesiol 2000;10:103-15.

Hubbard DR, Berkoff GM. Myofascial trigger points show spontaneous needle EMG activity. Spine 1993;18(13):1803-7.

Jensen C, Borg V, Finsen L, Hansen K, Juul-Kristensen B, Christensen H. Job demands, muscle activity and musculoskeletal symptoms in relation to work with the computer mouse. Scand J Work Environ Health 1998;24(5):418-24.

Jensen C, Finsen L, Søgaard K, Christensen H. Musculoskeletal symptoms and duration of computer and mouse use. Int $\mathbf{J}$ Ind Ergonom 2002;30:265-75.
Jensen C. Development of neck and hand-wrist symptoms in relation to duration of computer use at work. Scand J Work Environ Health 2003;29:197-205.

Jonsson B. Measurement and evaluation of local muscular strain in the shoulder during constrained work. J Human Ergol 1982;11:73-88.

Juul-Kristensen B, Laursen B, Pilegaard M, Jensen BR. Physical workload during use of speech recognition and traditional computer input devices. Ergonom 2004;47:119-33.

Juul-Kristensen B, Kadefors R, Hansen K, Byström P, Sandsjö L, Sjøgaard G. Clinical signs and physical function in neck and upper extremeties among elderly female computer users: the NEW study. Eur J Appl Physiol 2006;96:136-45.

Kourinka I, Jonsson B, Kilbom Å, Vinterberg H, Biering-Sørensen F, Andersson G, Jørgensen K. Standardised Nordic questionnaires for the analysis of musculoskeletal symptoms. Appl Ergon 1987;18:233-7.

Laursen B, Jensen BR, Garde AH, Jørgensen AH. Effect of mental and physical demands on muscular activity during the use of a computer mouse and a keyboard. Scand J Work Environ Health 2002;28: 215-21.

Madeleine P, Lundager B, Voigt M, Arendt-Nielsen L. The effects of neckshoulder pain development on sensory-motor interactions among female workers in the poultry and fish industries. A prospective study. Int Arch Occup Environ Health 2003;76:39-49.

Mathiassen SE, Winkel J, Hägg GM. Normalization of surface EMG amplitude from the upper trapezius muscle in ergonomic studies - a review. J Electromyogr Kinesiol 1995;5:197-226.

McNulty WH, Gevirtz RN, Hubbard DR, Berkoff GM. Needle electromyographic evaluation of trigger point response to a phychological stressor. Psychophys 1994;31:313-6.

Merletti R, Benvenuti F, Doncarli C, Disselhorst-Klug C, Ferrabone R, Hermens HJ, Kadefors R, Läubli T, Orizio C, Sjøgaard G, Zazula D. The European project 'Neuromuscular assessment in the elderly worker' (NEW): achievements in electromyogram signal acquisition, modelling and processing. Med Biol Eng Comput 2004;42(4):429-31.

Mortara DW. Digital filters for ECG signals. In: Computers in cardiology. Proceedings of Annual Conference of Computers in Cardiology. Long Beach, CA: IEEE Press; 1977. p. 511-4.

Nordander C, Hansson G-Å, Rylander L, Asterland P, Unge Byström J, Ohlsson K, Balogh I, et al.. Muscular rest and gap frequency as EMG measures of physical exposure: the impact of work tasks and individual related factors. Ergonom 2000;43:1904-19.

Pozzo M, Bottin A, Ferrabone R, Merletti R. Sixty-four channel wearable acquisition system for long-term surface electromyogram recording with electrode arrays. Med Biol Eng Comput 2004;42(4):455-66.

Sandsjö L, Melin B, Rissén D, Dohns I, Lundberg U. Trapezius muscle activity, neck and shoulder pain, and subjective experiences during monotonous work in women. Eur J Appl Physiol 2000;83:235-8.

Sjøgaard G, Søgaard K, Hermens HJ, Sandsjö L, Läubli T, Thorn S, Vollenbroek-Hutten MMR, et al.. Neuromuscular assessment in Elderly Workers with and without work related shoulder/neck trouble. The NEW-study design and physiological findings. Eur J Appl Physiol 2006;96:110-21.

Stroop JR. Interference in serial verbal reactions. J Exp Psychol 1935;18:643-61.

Vasseljen Jr O, Westgaard RH. A case-control study of trapezius muscle activity in office and manual workers with shoulder and neck pain and symptom-free controls. Int Arch Occup Environ Health 1995;67:11-8.

Veiersted KB, Westgaard RH, Andersen P. Electromyographic evaluation of muscular work pattern as a predictor of trapezius myalgia. Scand $\mathrm{J}$ Work Environ Health 1993;19:284-90.

Wahlström J, Lindegård A, Ahlborg Jr G, Ekman A, Hagberg M. Percieved muscular tension, emotional stress, psychological demands and physical load during VDU work. Int Arch Occup Environ Health 2003;76:584-90.

Wahlström J, Hagberg M, Toomingas A, Wigaeus Tornqvist E. Percieved muscular tension, job strain, physical exposure and associations with neck pain among VDU users; a prospective cohort study. Occup Environ Med 2004;61:523-8. 
Wigaeus Tornqvist E, Eriksson N, Bergqvist U. Risk factors at computer and office workplaces. In: Marklund S, editor. Worklife and Health in Sweden 2000. Stockholm: National Institute for Working Life; 2001. p. $189-213$.

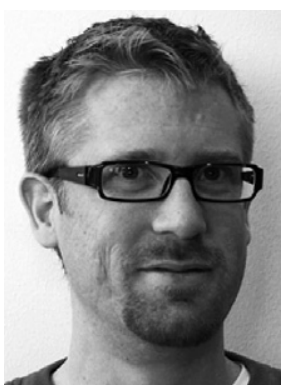

Stefan Thorn was born in Växjö, Sweden, in 1971. He received his Ph.D. (Ergonomics) in 2005 at Chalmers University of Technology (CTH) in Göteborg, Sweden, where he also completed his M.Sc. in Mechanical Engineering. His Ph.D. focused on intramuscular electromyography and pathomechanisms for muscle pain in light manual work. Thorn is currently working as a researcher at the National Institute for Working Life in Göteborg. Special area of interest is development of tools for detection and prediction of workrelated musculoskeletal disorders.

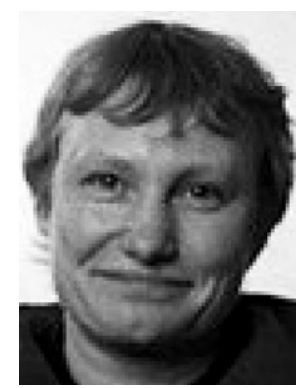

Karen Søgaard received the M.Sc. in Physical Education from the August Krogh Institute, University of Copenhagen and at the same institution she pursued a Ph.D. in Human Physiology in 1994. Currently she is a Senior Researcher at Department of Physiology at the National Institute of Occupational Health, Denmark. Her main field of competence is human exercise physiology with focus on muscle mechanics, metabolism and fatigue. She is involved in experiments focused on kinetics, motor unit activity, motor coordination and muscle fatigue in humans and the relation to musculoskeletal disorders.

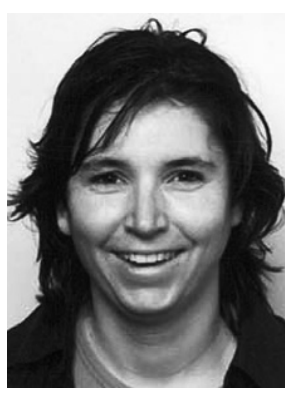

Laura Kallenberg was born in Amsterdam, the Netherlands, in 1978. She graduated summa cum laude in Electrical Engineering at the University of Twente, Enschede, The Netherlands, in 2002. Her M.Sc. thesis was on motor unit activation patterns in people with chronic pain. Currently she is a Ph.D. student at Roessingh Research and Development, Enschede, The Netherlands where she is working on the application of multi-channel surface EMG techniques to investigate mechanisms underlying work-related chronic pain. Her research interest is in the area of surface EMG signal processing for investigating neuromuscular disorders.

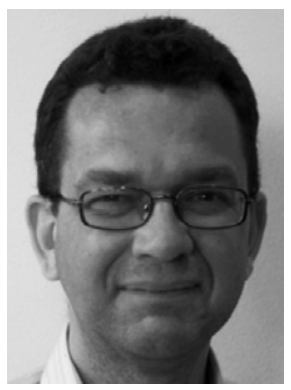

Leif Sandsjö received his masters' degree in medical electronics from Chalmers University of Technology (CTH), Göteborg, Sweden, in 1981. After working for the Swedish Telecom and Ericsson he turned to research and presented his $\mathrm{PhD}$ thesis in 2004. He is currently holding a Postdoctoral fellow-position at the National Institute for Working Life, Göteborg, Sweden, doing research in field-based methods to acquire information on work exposure, especially electromyographic signals, to assess work-related neck- and shoulder problems. A special research interest concerns prevention of work-related musculo- skeletal disorders by means of applying bio/myofeedback techniques at the workplace.

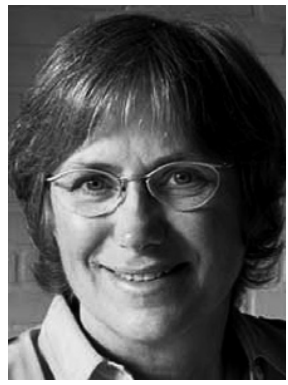

Gisela Sjogaard completed M.Sc. degrees in Mathematics and Physical Education and earned in 1979 her Ph.D. in Muscle Physiology at the faculty of Natural Science and her Dr.Med.Sc. in 1990 at the faculty of Medicine at the University of Copenhagen. She is currently appointed as professor in Exercise Physiology at the National Institute of Occupational Health, Denmark. Her main field of competence is human exercise physiology with focus on muscle mechanics, metabolism and fatigue. Special area of interest is neuromuscular control and biomechanics, using kinematics, kinetics and electromyography including single motor unit recordings.

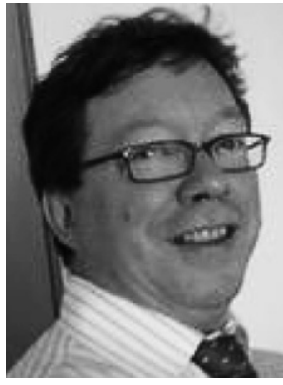

Hermie J. Hermens is full professor in neuromuscular control of human movements at the University of Twente, the Netherlands, and cluster manager at Roessingh Research and Development, where he is responsible for the research area of the non-invasive assessment of neuromuscular functions. He was president of the International Society of Electrophysiology and Kinesiology (ISEK) and coordinator of the Seniam project on standardization of surface EMG measurements. His research is focused on normal and impaired motor control, using surface Electromyography with applications in chronic pain, stroke and work related disorders.

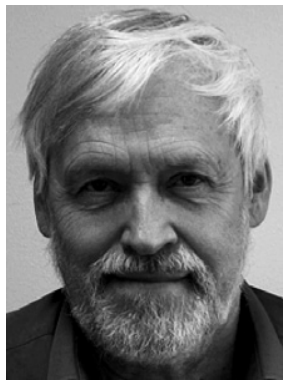

Roland Kadefors received his $\mathrm{Ph} . \mathrm{D}$. (Medical Engineering) at Chalmers University of Technology (CTH) in Göteborg, Sweden, in 1972. He has carried out research in neurophysiology, rehabilitation engineering and ergonomics, and has held an Adjunct Professorship in Applied Ergonomics with CTH since 1978. He is currently a senior researcher at National Institute for Working Life in Göteborg, and is on the editorial boards of International Journal of Industrial Ergonomics, and Journal of Electromyography and Kinesiology. He has carried out research in neurophysiology, orthopaedics, rehabilitation, ergonomics, and occupational health.

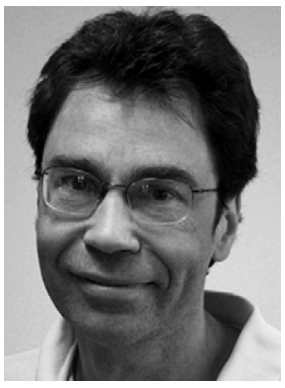

Mikael Forsman received the M.Sc. degree in 1987 (Electrical Engineering) at Chalmers University of Technology (CTH) in Göteborg, Sweden, and in 1995 his Ph.D. in Medical Engineering. Since 1999 he is Associate Professor in Ergonomics at $\mathrm{CTH}$, where he also has been teaching analogue and digital signal processing. His research interests are EMG signal processing, muscle pain in light manual work, ergonomic evaluation methods, and participative ergonomics. He is currently a senior researcher and assistant head of the department of People, Technology, Organisation at the National Institute for Working Life in Göteborg. 